\title{
Rhodium Cross-Stitching Sews Up Dibenzofulvalenes
}

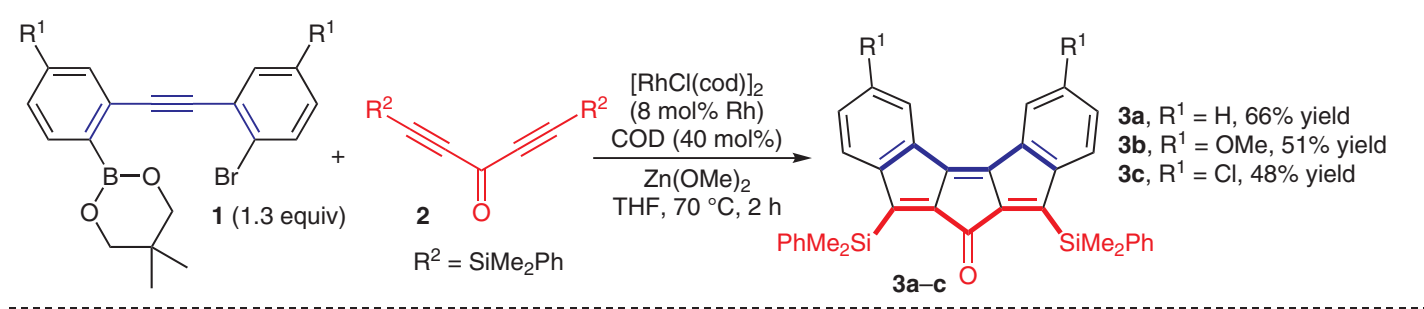

Selected examples of product diversification:
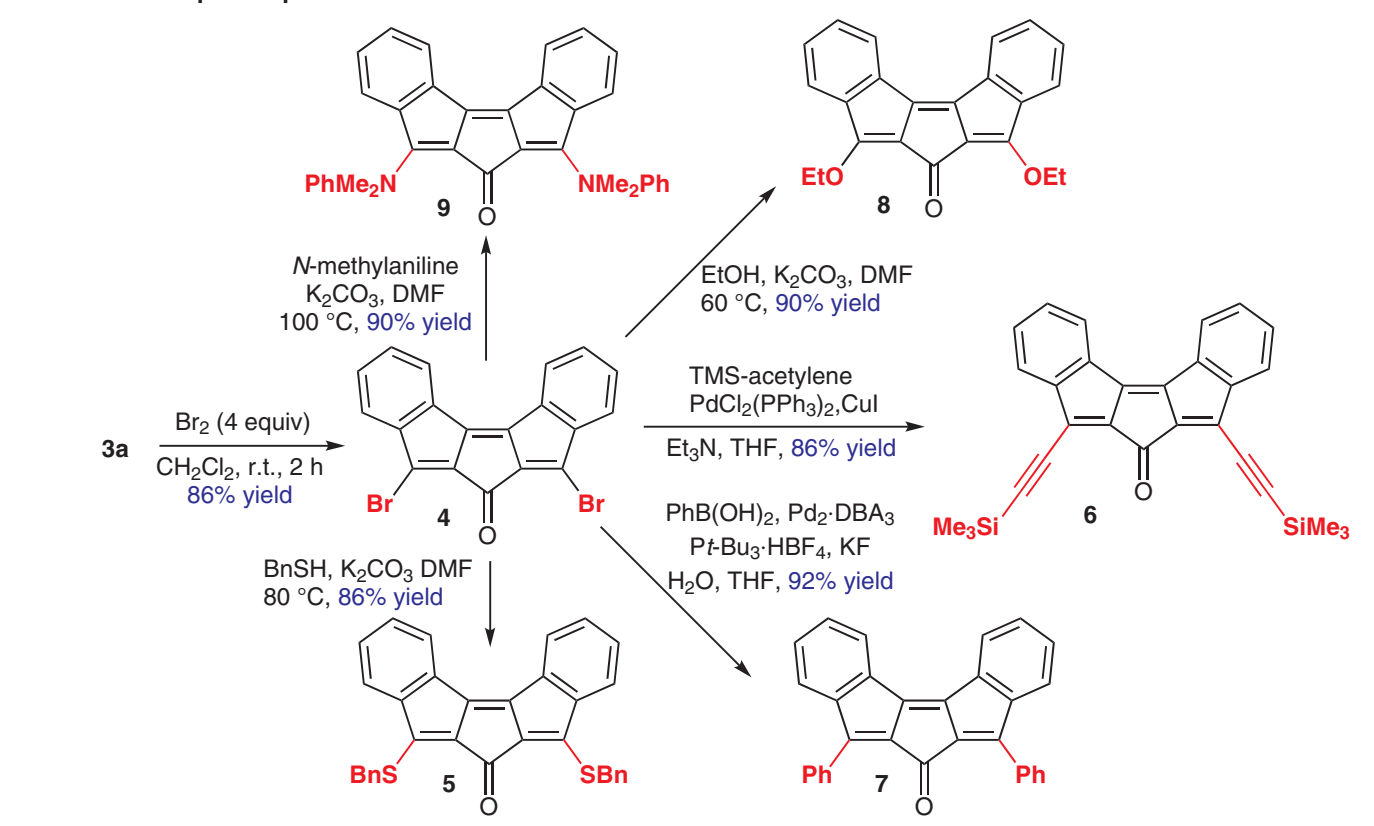

$\mathrm{Pt}-\mathrm{Bu}_{3} \cdot \mathrm{HBF}_{4}, \mathrm{KF}$

$\mathrm{H}_{2} \mathrm{O}, \mathrm{THF}, 92 \%$ yield

Alternate bridging groups:
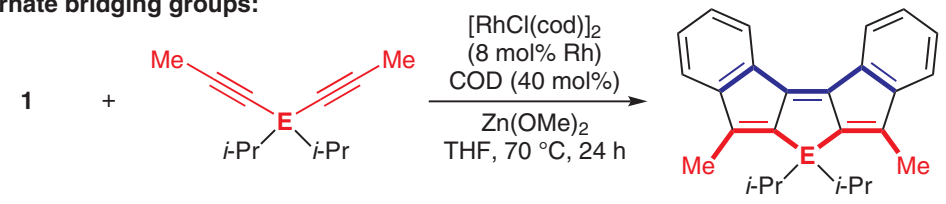

$10, \mathrm{E}=\mathrm{Si}, 62 \%$ yield $11, \mathrm{E}=\mathrm{Ge}, 52 \%$ yield

Significance: Extended conjugated aromatic molecules possess unique optoelectronic properties that have proven critical for the development of functional materials. Conventional methods for the construction of such polycyclic structures are often linear, iterative processes that hinder scale-up and further development. This method provides hitherto unreported carbonyl-bridged dibenzofulvalenes in a single step by an alkyne insertion cascade.
Comment: Zinc methoxide uniquely enables boronic ester $\mathbf{1}$ and ketone $\mathbf{2}$ to undergo coupling and cyclization via rhodium(I) catalysis, affording a modest variety of products. Compound 3 a can be efficiently transformed into dibromide $\mathbf{4}$, and the latter compound is easily diversified into a variety of substituted compounds possessing a range of optical and electronic properties. Finally, this method proved able to furnish C-, Si-, Ge-, S-, and Pbridged structures. 